\title{
UNHCR and the pursuit of international protection: Accountability through technology?
}

Katja Lindskov Jacobsen \& Kristin Bergtora Sandvik

Copy submitted November 2017.

To cite this article: Katja Lindskov Jacobsen \& Kristin Bergtora Sandvik (2018): UNHCR and the pursuit of international protection: accountability through technology?, Third World Quarterly To link to this article: https://doi.org/10.1080/01436597.2018.1432346

\begin{abstract}
Better management and new technological solutions are increasingly portrayed as the way to improve refugee protection and enhance the accountability of humanitarian actors. Taking concepts of legibility, quantification and co-production as the point of departure, this article explores how techno-bureaucratic practices shape conceptions of international refugee protection. We do this by examining the evolving roles of results-based management (RBM), biometrics and cash-based interventions as 'accountability technologies' in the United Nations High Commissioner for Refugees' international protection efforts. The article challenges the assumption that these technologies produce a seamless form of accountability that is equally attentive to donor requests and the protection needs of refugees. By focusing on how the constitution of these techniques as 'accountability solutions' shapes conceptions of the very meaning of protection (i.e. the problem to be addressed), we also show what dimensions of protection gets omitted in this co-production of technical solutions and socio-political problems.
\end{abstract}

\section{Keywords}

UNHCR, cash, biometrics, results-based management, refugees, accountability, technology, STS

\section{Introduction}

A deep political struggle over the future of international refugee protection, including what it means to be accountable to the letter and spirit of the 1951 Refugee Convention, is shaking the international refugee regime to its core. Within the humanitarian sector, tighter management approaches, the increased legibility of displaced populations and more effective aid delivery are understood to improve protection, whilst also enhancing the accountability of humanitarian 
actors tasked with providing such protection. Focusing on the United Nations High Commissioner for Refugees' (UNHCR) use of results-based management, biometrics and cashbased interventions (CBIs), this article argues that more attention must be given to the ways in which techno-bureaucratic practices, independently, chronologically and in combination have shaped the understanding of international refugee protection, and the promise of accountability.

Much of the critical protection literature, emerging from a concern with humanitarian power and accountability, engages with UNHCR's international protection efforts either by offering a narrative of lack, including lack of professionalism, capacity, courage ${ }^{1}$, and political clout $^{2}$; or by attempting to unpack humanitarian governance and its discontents through a focus on refugee status determination procedures ${ }^{3}$, resettlement ${ }^{4}$, or camp management ${ }^{5}$. However, so far, little attention has been given to how initiatives to enhance legibility and quantificationas techniques of humanitarian governance ${ }^{6}$ - have shaped the conceptualization of international protection and attendant ideas about accountability.

To that end, this article brings together insights from debates about how legibility and quantification practices affect refugee protection, with an exploration of how technical accountability solutions and resulting framings of protection problems are co-constituted. ${ }^{7}$ Taking this focus on legibility, quantification and co-production as our point of departure, the article uses insights from socio-legal scholarship and science and technology studies (STS) to explore three topical examples, namely the evolving roles of results-based management (RBM), biometrics and cash-based interventions (CBIs) as 'accountability technologies' in UNHCR's protection efforts. We are interested in how these technologies are deployed to create pools of eligible individuals, distribute them into categories and then deliver value (aid) accordingly, with the promise of 'performing accountability' by performing these tasks in the most effective, efficient, fast, precise, cheap, comprehensive and transparent manner possible.

An important aim of this investigation is to open a broader inquiry into how contemporary practices of international aid organizations are shaped by RBM, biometrics and CBIs, about the accountability issues that specific solution/problem framings risk omitting, and about emerging interfaces between these accountability technologies. We argue that this

\footnotetext{
${ }^{1}$ Verdirame and Harrell-Bond, Rights in Exile

${ }^{2}$ Suhrke and Newland, Uphill into the Future; Pallis, 'The Operation of UNHCR's accountability mechanisms'

${ }^{3}$ Kagan, 'Is Truth in the Eye'

${ }^{4}$ Sandvik, Blurring Boundaries

${ }^{5}$ Wilde, Quis Custodiet Ipsos Custodes; Barnett, Humanitarianism with a Sovereign Face; Slaughter and Crisp, A Surrogate

State?; Crisp, State of Insecurity.

${ }^{6}$ Barnett, 'Humanitarian governance'

${ }^{7}$ We are here inspired by Abdelnour and Saed, Technologizing Humanitarian Space
} 
configuration and use of accountability technologies contributes to the emergence of a particular understanding of international protection as a task best accomplished through improved techno-bureaucratic legibility and quantification practices. We also challenge the assumption that the outcome is a seamless, dual direction accountability that is equally relevant and attentive to donor requests and the protection needs of refugees.

The article proceeds as follows: we begin by outlining the role and import of accountability in UNHCR's international protection mandate. We then offer a descriptive account of the growth and evolution of RBM, biometrics and CBIs as accountability solutions. Next, we explore how the framing of these technologies as solutions contributes to a particular framing of refugee protection problems, before mapping out a set of crosscutting issues and challenges to UNHCR's refugee governance. A brief conclusion follows.

\section{Accountability and a mandate of international protection}

As the key international actor mandated to protect refugees globally, UNHCR currently exercises extensive governance functions over an unprecedented number of individuals. Following decades of criticism about UNHCR's lack of accountability and struggles with fulfilling its mandate to protect refugees ${ }^{8}$, the introduction of new accountability mechanisms to strengthen "accountability to affected populations" — defined as a commitment "to use power responsibly by taking account of, giving account to and being held to account by the people they seek to assist" - has become an institutionalized feature of international refugee management ${ }^{10}$. Yet, for UNHCR, "affected populations" are not the sole focus of its accountability efforts; it also holds itself accountable to donors, to the broader international community, and to its overall mandate, which is to provide international protection to refugees. One result is potentially conflicting demands: donors, for example, may in practice place greater emphasis on accountability for how effectively, efficiently or strategically UNHCR spends donor funding, rather than on accountability to affected populations.

UNHCR's accountability to its protection mandate is both the objective of its everyday efforts and an overarching normative value. Although it would at first seem that UNHCR's mandate is a given, we suggest that international protection is not reducible to these aspects of the response - that is, the application of international refugee law and the implementation of UNHCR programs. International protection is also produced through institutional practices,

\footnotetext{
${ }^{8}$ Loescher, 'UNHCR and the erosion of refugee protection'

${ }^{9}$ UNHCR Emergency Handbook, 2015:1

${ }^{10}$ Sandvik and Jacobsen, 'UNHCR and the struggle for accountability'
} 
including techno-bureaucratic ones. Exploring these practices, separately and together, help us unpack the constitutive dynamics of protection efforts and their attendant governance effects.

UNHCR adopted RBM in 1998. In 2002, it began its first trial with biometrics in Pakistan. The organization offered cash assistance to repatriating Afghan refugees in Pakistan already back in $1990^{11}$, but what is now known as 'the dash for cash' began around 2012-13, closely linked to the implementation of UNHCR's RBM-objectives and developments in biometric registration. UNHCR's account of the implementation of these techno-bureaucratic accountability technologies is a progress narrative about simultaneous paths to improved upward and downward accountability. To the degree that scholars have engaged with these and similar initiatives, they have focused on the gap between ideals, plans, and implementation. However, we know little about the relationship between these 'accountability technologies,' or about their joint effects on "dual direction" accountability in international refugee management. This article begins to bridge that knowledge gap.

\section{Accountability and international protection as techno-science}

Stevens (2016) observe that "there is no single, uniform response that can be labelled 'protection'. ${ }^{12}$ Instead, protection is a fluid concept that varies in accordance with temporal and spatial factors. ${ }^{13}$ International protection means different things to different actors, both inside UNHCR and within refugee management more generally. We suggest that even amid such fluidity, UNHCR's accountability efforts entail discursive and material practices through which international protection acquires meaning (and momentary stability). To enrich our understanding of the meanings assigned to international protection, we propose to add two additional perspectives: First, we argue that international protection gains meaning from a set of discursive and material elements. Second, focusing on discursive and material aspects of UNHCR's protection efforts, we then zero in on the often-overlooked politics of three technobureaucratic measures introduced to aid UNHCR's quest for accountability.

By exploring RBM, biometrics and CBIs as techno-bureaucratic 'accountability technologies', we illustrate how discursive and material aspects of these technologies contribute to the constitution of meaning, as well as to the constitution of new protection needs. Our analysis challenges the prevalent UNHCR-assumption that these practices will necessarily

\footnotetext{
${ }^{11}$ Crisp, 'Repatriation under Conflict'

12 Stevens, 'Rights, Needs or Assistance?'

${ }^{13}$ Also Storey, 'The Meaning of "Protection" within the Refugee Definition'.
} 
enhance accountability toward both refugees and donors; in fact, we suggest that instead of improving accountability, these practices may give rise to critical accountability gaps.

Our conceptual frame takes as its point of departure the interface of STS and law and society scholarship, which in recent years has emerged as a productive site of scholarly inquiry $^{14}$, but which rarely has been used to study international refugee protection ${ }^{15}$. We propose that the tools used as 'accountability technologies' can be construed as a form of 'techno-science, ${ }^{16}$ : ordering practices that are materially productive, giving meaning to the "how," "whom," and "what" of international refugee protection in ways that may eschew the distribution of accountability in international refugee protection, and paradoxically produce new protection needs. Importantly, these 'technical' measures thus have explicitly political dimension that should not go unnoticed as they may otherwise risk when framed simply as 'technical' - rather than political - matters ${ }^{17}$. Here we focus on two aspects of this form of coproduction $^{18}$ : how practices and discourses contribute to the production of legibility and quantification; and to temporarily producing a 'problem/solution' framing within which 'international protection' acquires a specific meaning.

Legibility, the 'seeing' of citizens and communities that according to Scott (1998) was central to the making of the modern state ${ }^{19}$, gains specific importance in humanitarian contexts. Not only in regard to the humanitarian imperative to address 'needs' but also with respect to political concerns about corruption, beneficiary 'fraud' and violent extremism. In these contexts, making non-citizens (displaced persons) legible becomes central as it functions as a precondition for offering 'accountable' protection. Legibility is produced through the intertwining of technological, managerial and normative (legal) approaches,${ }^{20}$ and through the generalized datafication of the humanitarian sector. ${ }^{21}$ In this context, legibility is both part of the solution and a 'problem' that gets constituted: legibility becomes a measure of success whilst at the same time productive of specific framings of refugee protection as a problem. Conversely, the humanitarian sectors move to new public management and RBM, and more recently biometrics and CBIs, has contributed to an increasing 'quantification culture' also in this domain. The push for measurements engenders a framing of social life — and its problems -

\footnotetext{
${ }^{14}$ Cole and Bertenthal, "Science, Technology, Society, and Law."

${ }^{15}$ But Franke, 'Refugee registration as foreclosure'

${ }^{16}$ Asdal, Brenna, and Moser, Technoscience.

${ }^{17}$ Jasanoff, Science at the Bar

${ }^{18}$ Jasanoff, States of knowledge

${ }^{19}$ Scott, Seeing like a state

${ }^{20}$ Following an embrace of the rule of law as an engine of progress (Lohne and Sandvik, 'Bringing law'), we have seen 'a dramatic expansion of efforts to measure and quantify legal systems' (Krever, 'Quantifying law'132).

${ }^{21}$ Sandvik, Jacobsen and McDonald, 'Do no harm'.
} 
that lends itself to a focus on aspects of 'the social' that can be (or be made) classified/classifiable, counted/countable. Importantly, these indicators and quantifiable aspects are then bundled into more complex representations, with an aura of 'objective truth' and 'scientific authority" ${ }^{22}$. As noted by critics, this emphasis on quantification may engender a reductive form of accountability resulting from distilling social life into too 'neat categories' 23 , including obscuring the role of human judgement, political considerations, logistical constraints, human errors, and technical malfunctions.

\section{Protection through the production of accountability solutions}

In this section, we contextualize and explore how RBM, biometrics and CBIs have been designated as 'accountability technologies' in UNHCR's protection work. RBM entered the humanitarian realm as a form of new public management (NPM). According to NPM, viewing the public as a consumer operating within a free-market system implicitly "ensure accountability and transparency to the tax-payer". ${ }^{24}$ UNHCR' turned to RBM in 1998 in response to media attention and a series of critical reports by the Office of Internal Oversight Services (OIOS), the UN internal watchdog. ${ }^{25}$ UNHCR defines RBM rather loosely, as "a philosophy that emphasizes the achievement of results as the essential task of management" 26 , and argues (1) that RBM can help realize its protection mandate, and (2) that "accountability is being strengthened through an emphasis on global coherence, transparency, participation, impact, and performance measurement and analysis". ${ }^{27}$ RBM has also been described as the platform for achieving "the right results in the most efficient and effective manner". ${ }^{28}$ The incremental launch of RBM, which began with the introduction of $\log$ frames, led to a number of in-house initiatives designed to improve UNHCR's ability to demonstrate how its resources were being used and with what result. ${ }^{29}$ By 2006, UNHCR initiated a far-reaching internal reform process to increase efficiency and improve service delivery. The organization introduced a comprehensive package of six RBM-related concepts and initiatives: The Comprehensive Needs Assessment; Initial Budget Targets and the prioritization process; the Global Strategic Priorities; the Results Framework; the implementation of the Focus

\footnotetext{
${ }^{22}$ Merry, The Seductions: 29

${ }^{23}$ Merry ibid.

${ }^{24}$ Ramalingam, Mitchell, and Smart, 'Counting What Counts'

${ }^{25}$ See for example Burns and Williams, 'Refugee's Agency Lost in Wilderness'

${ }^{26}$ UNHCR, 'Practical guide'

${ }^{27}$ Turk and Eyster, 'Strengthening Accountability in UNHCR'.

${ }^{28}$ Ibid.

${ }^{29}$ Kelley, Sandison, and Lawry-White, 'Enhancing UNHCR's Capacity'.
} 
management software, and a new budget structure. ${ }^{30}$ With its emphasis on effectiveness, efficiency, and "value for money," RBM has been portrayed as an essential tool for ensuring upward accountability to donors and the executive committee. ${ }^{31}$ Yet the appeal of RBM was also linked to its presumed ability to enhance downward accountability, ${ }^{32}$ by providing "a methodology for UNHCR to enhance its responsiveness and thereby its accountability to the populations it serves". ${ }^{33}$ We suggest that this promise of dual-direction accountability is also co-produced through UNHCR's multiplicity of framings of RBM: as an accountability driver that provides value for money vis-à-vis donors and political constituencies; provides value for money by indirectly optimizing international protection; improves protection by providing access to a more reliable and effective toolbox; and is normatively more attractive: that is, by providing better protection, it inherently provides greater accountability to people of concern.

Biometrics arrived later than RBM in UNHCR operations. While biometrics had been around for some time, UNHCR first deployed iris-recognition technology in 2002, when repatriating refugees returning from Pakistan to Afghanistan. ${ }^{34}$ In 2003 and 2006, UNHCR also introduced biometrics in refugee camps in Tanzania and in Malaysia, respectively; in the case of Malaysia, UNHCR referred to biometrics as "a new direction" in refugee registration. ${ }^{35}$ Since then, UNHCR has used biometrics in a number of additional locations, ${ }^{36}$ and in 2013 , UNHCR tested a 'version 2' of its biometric refugee registration system: a multimodal system piloted in the Dzaleka Refugee Camp, in Malawi. The piloting of this 'version 2' coincided with the release, in 2013, of a Request for Proposal for s Biometric Management System - a document in which UNHCR also describes its long-term ambitions regarding the use of biometrics in refugee management. ${ }^{37}$ As was the case with RBM, the appeal of the new technology was linked to the expectation that upward and downward accountability would be improved in various ways, for example with respect to speed and accuracy. Biometrics is expected to speed up refugee registration, and thereby improve UNHCR's ability to promptly assist refugees. This advantage was stressed, for example, in accounts of how biometrics helped UNHCR speed up registration of Syrian refugees. ${ }^{38}$ Moreover, because biometrics rely on unique physical characteristics, they enable UNHCR to catch those who try to cheat the system (fraud

\footnotetext{
30 Allen and Rosi, 'Measure for Measure'.

${ }^{31}$ Sandvik, 'How accountability technologies shape international protection'

32 Bradley, 'Accountability for IDP Protection in Colombia'.

33 Turk and Eyster, 'Strengthening Accountability in UNHCR'.

${ }^{34}$ A technology that captures a digital image of the unique pattern in the coloured portion of the eye that surrounds the pupil

35 Ismail and McKinsey, 'Fingerprints Mark New Direction in Refugee Registration'.

36 Jacobsen, 'On humanitarian refugee biometrics'

37 UNHCR, 'Request for Proposal'

38 Alsalem and Riller 'UNHCR slashes waiting time'
} 
prevention), thereby ensuring a fairer distribution of scarce resources. This unparalleled accuracy is also expected to result in more accurate refugee population data, thereby enhancing accountability toward donors. In sum, UNHCR perceives biometrics as enhancing downward accountability (by enabling "faster" and "fairer" refugee assistance) and enhancing upward accountability (by providing more accurate registration and population data).

While UNHCR has given cash to refugees for decades, CBIs have only recently been scaled up. In 2016, UNHCR operated CBIs in 60 countries, with Lebanon, Afghanistan and Jordan as the largest programs. ${ }^{39}$ The most common form of cash includes unconditional cash transfers, conditional cash transfers and vouchers. The commitment to institutionalize CBIs and how to do this has been set out in a number of recent policy documents ${ }^{40}$, accompanied by CBI Standard Operating Procedures to "ensure that CBIs are designed and implemented within UNHCR's results-based management, financial and legal frameworks". ${ }^{41}$ An important vehicle for cash interventions is UNHCR's mainstreaming of biometric registration through EyeCloud making the refugee population more legible through compliance with the increasingly important KYC (know your customer) requirements ${ }^{42}$. The rise of cash interventions is fuelled generally by the datafication of humanitarian action and more specifically by the possibility of capitalizing on biometrics, which is presumed to ensure donor support "given the associated increased accountability". Iris scans eliminate concerns about lost pin codes, and reduces 'negative coping mechanisms'. ${ }^{43}$ Across the humanitarian sector, while percentages vary, there is a claim that cash assistance reduces the number of recipients living below the poverty line. ${ }^{44}$ By increasing autonomy, CBI's 'address protection risks' ${ }^{45}$ In this regard, CBI's are also vehicles for achieving the objectives of UNHCR's resilience policy. UNHCR claims that CBIs "offer refugees a cost-effective tool that can empower them to determine and meet their own needs, increasing dignity, choice and protection, both during displacement and upon return". ${ }^{46}$ As a dual-direction accountability technology, UNHCR expects CBIs to improve effectiveness, bring efficiency gains, contribute to poverty alleviation and generally empower refugees as customers.

\footnotetext{
${ }^{39}$ UNCHR, 'Cash Facts 2016'

${ }^{40}$ UNHCR, 'Policy on Cash'

${ }^{41}$ UNHCR, 'Operational guidelines'

${ }^{42}$ Gilert and Austin, 'Review of the Common Cash Facility'.

${ }^{43}$ UNHCR, 'Cash-Based Interventions'

${ }^{44}$ Riecke, 'Refugees and Humanitarian Assistance'

${ }^{45}$ UNHCR, 'Cash-Based Interventions'

${ }^{46}$ UNHCR, 'Cash-Based Interventions'
} 
From a co-productionist perspective, these examples illustrate how UNHCR has over time framed and rolled out different but interlinked solutions to critics (including donors) voicing concerns about a lack of accountability in UNHCR's protection practices.

\section{From 'solutions to co-produced framings of 'problems'}

In this section we shift the focus towards how accountability technologies also contribute to 'problem framing' - and how this also leaves actors, processes and events unproblematized. Early RBM evaluations identify specific challenges to UNHCR's RBM implementation, centring on UNHCR's operating environment, and the attendant difficulty of obtaining 'good data'. A 2007 OIOS report noted that in addition to often functioning under emergency conditions, UNHCR is affected by the inherent unpredictability of population movements and national government policies; the expansion of target populations to include internally displaced persons and other people of concern, beyond "traditional" refugees; and the proliferation of actors in the field. The report noted that UNHCR "needs to shape its approach to RBM based on the unique needs and characteristics of the organization". ${ }^{47}$ Nevertheless, a failure to produce 'good' data could jeopardize the RBM effort: a 2010 evaluation emphasizes the importance of ensuring that country-level data is accurate, comprehensive, and consistent, so as to enable meaningful cross-country comparisons and aggregated global results. ${ }^{48}$ Moreover, in a context that puts value on quantification, the production of 'good data' on the output and impact in 'hard-to-measure' areas such as protection, advocacy, capacity building, and legislative reform (in contrast to areas such as service delivery) is generally a challenge for UNHCR. ${ }^{49}$

However, attention must also be given to how the emergency context shape not only how well UNHCR is able to implement RBM, but also the manner in which RBM shapes the framing of protection problems through obscuring knowledge about causal relationships and bureaucratizing protection practices. Assessments have pointed out that UNHCR's complex RBM efforts risk introducing a structural disjuncture between RBM-initiatives and protection outcomes. A 2011 assessment found that UNHCR's results frameworks did not fully define, communicate, guide, or monitor how its mandate is translated into organization-wide results. ${ }^{50}$ While UNHCR was perceived to make contributions to humanitarian results, neither its reports nor its performance measurement systems provided a clear and complete picture of how it was

\footnotetext{
${ }^{47}$ UN OIOS, 'Inspection'.

${ }^{48}$ UN OIOS, 'Audit of Focus'.

${ }^{49}$ See generally Dunlop, 'Indications of progress'.

${ }^{50}$ MOPAN, 'Synthesis report'
} 
improving the circumstances and well-being of persons of concern. ${ }^{51}$ UNHCR's RBM activities have also been criticized for discrepancies between intent and implementation. One of the rationales for RBM is that it yields performance information, which can be used to inform decisions about a project, and to improve performance. ${ }^{52}$ Nevertheless, OIOS (2007) found that although staff spends a large portion of their time on data collection, performance monitoring, and reporting, they sensed that "there is little payoff to these activities, as feedback is rarely given on the information they produce and performance data are rarely seen being used in actual decision-making" $" 53$.

Similarly, with the framing of biometrics as a solution to accountability criticism, what also gets produced is a particular framing of the problem of accountability in refugee protection. For with a focus on speed and accuracy, the problem of accountability in UNHCR's protection efforts is reduced to a concern with processing of high numbers and with accurate population figures as requested by donors. What is given less attention within this framing of solutions/problems is the question of 'downward' accountability. With scarce resources, being accountable means ensuring that aid reaches as many refugees as possible. To achieve this (and to respond to fraud allegations), UNHCR looked to biometric registration" ${ }^{54}$ to "catch duplications" ${ }^{" 55}$. Yet, in framing biometrics as an accountability solution, UNHCR also contributed to the production of a specific framing of 'the problem'. In this framing, risks may be overlooked because of how 'biometrics as solution' places greater emphasis on 'upward accountability' (e.g. ensuring that aid does not reach potential terrorists), than on 'downward' accountability (protection, also of biometric refugee data). To further illustrate which accountability problems are overlooked in this framing let us consider some of the concerns voiced by refuges.

For example, the risk that actors with other aims than refugee protection may gain access to the data, has been raised on different occasions. Recently in relation to the Rohingya refugee crisis $^{56}$, but also in the context of Syrian refugees concerned about the Lebanese government requesting access to UNHCR's biometric refugee data - notably given the lack of an official UNHCR stance on the issue ${ }^{57}$. Earlier this year, the Malaysian government called on

\footnotetext{
${ }^{51}$ MOPAN ibid.

${ }^{52}$ UNHCR, 'Practical guide'

${ }^{53}$ UN OIOS, 'Inspection',24

${ }^{54}$ UN News 2004

${ }^{55}$ UNHCR, 2006

${ }^{56}$ Rahman 2017

57 Jacobsen, 2016
} 
UNHCR to share its biometric data of refugees ${ }^{58}$. Even if it is impossible to find out whether biometric refugee data and biometric terrorist data have been cross-matched, it is important to note that unlike population figures, which are aggregate, biometric data used to confirm the identity of a given person is individual - a difference with important implications for 'downward accountability'. I.e. biometric registration may, in certain contexts, create security concerns that could prevent some refugees from registering with UNHCR. This has been the case with Syrian refugees in Lebanon; further investigation is needed to see whether such effects have been observed in other contexts too. In sum, with this co-constitution of biometric as solution and upward accountability as the foremost 'problem', important security dimensions are rendered invisible, notably concerning refugee protection and safety.

Finally, presently the problems with CBIs are largely framed as (1) the continuing under-deployment of CBIs across the humanitarian sector; and (2) as technical: While beneficiaries have overcome previous problems in accessing ATMs through iris scans, it is noted that there continues to be technological issues which occasionally prevent beneficiaries from accessing their cash smoothly, including over-sensitivity of cameras at the ATMs which cannot read all iris scans, interference due to direct sunlight and maintenance issues. ${ }^{59}$ Persistent concerns such as risks of corruption, gender-based violence and security concerns can be overcome through "good program design" and monitoring. ${ }^{60}$

Importantly, CBIs are also constitutive technologies. UNHCR now frames protection through CBI in direct contrast to its own (and ongoing) traditional approaches: "Protection is first and foremost ensured by not stigmatising the refugee through, for example, distribution of in-kind assistance at designated centres". ${ }^{61} \mathrm{CBIs}$ are also co-constitutive of a particular conception of who does not need protection and of how this determination is made. 'UNHCR's VAF' (Vulnerability assessment framework) was launched in Jordan in 2014 to develop a 'robust model' to map vulnerabilities of the Syrian non-camp population. ${ }^{62} \mathrm{VAF}$ is promoted as a central, homogenizing tool for identifying and ranking vulnerability, where an analysis of the data calculates a vulnerability "score" that UN agencies and INGOs can use to identify households needs and vulnerabilities. Yet, initial reviews of secondary data and meetings with partners of UNHCR revealed that in the case of cash, UNHCRs partners used different systems for identifying vulnerability: a number of partners had adopted a scorecard approach, but

\footnotetext{
${ }^{58}$ Lee, 2017

${ }^{59}$ Gilert and Austin, 'Review of the Common Cash Facility', 16.

${ }^{60}$ Berg and Seferis, 'Protection outcomes'.

${ }^{61}$ Schimmel, 'UNHCR Cash programming'.

${ }^{62}$ UNHCR, 'RAIS'.
} 
different partners used different scorecards. ${ }^{63}$ In the context of the debate around the cashprogramming in Lebanon, a commentator voiced concerns about a "system that doesn't see people but data sets, no individuals but numbers, no families but scores", where families lose cash assistance as a consequence of being shifted between categories of vulnerability. The commentator noted that “these families haven't turned down a magical road to a better life, but a data set, based on an annual registration process, has decided their fate for them" ${ }^{\circ}$. Given the difficulties of context, the fallibility of technology and the persistent challenges in implementing and streamlining approaches, the view of CBI's as a 'game changer' for refugee protection obscures its constituent effects on the conceptualization of refugee protection and who is in need of it.

\section{Crosscutting issues: Universality and new protection needs}

This section explores two crosscutting issues that highlight the role of techno-bureaucratic practices in shaping meaning and value of protection: the claim of universality, and the rise of new protection needs. Türk and Eyster explain that in an effort to "modernize" the understanding of accountability, it has been assigned "a more benign, universal meaning" 65 . UNHCR's embrace of accountability technologies (which stems, in part, from claims of universality) is in keeping with this trend. UNHCR's assumptions about a universal understanding of accountability — that includes viewing global, equitable protection to refugees as key to accountability - are reflected in beliefs about the universality of techno-bureaucratic measures: RBM, biometrics and CBIs are thought of as neutral, universally applicable tools that can straightforwardly support the realization of accountability principles. We suggest that an analysis of the constitutive effects of these techno-bureaucratic practices challenges both the assumption that it is possible to work from a "universal" notion of accountability, and the notion that universal accountability can be achieved through a uniform set of techno-bureaucratic practices. UNHCR offices perform at very different levels under very different circumstances; if the only things required for good outcomes were identical techno-bureaucratic practices, then all UNHCR offices should perform at the same level—but that's not the case.

In the case of RBM, for example, the presence of guidelines, training, adequate software, and insistent demands from Geneva does not automatically yield more consistent data

\footnotetext{
${ }^{63}$ Khogali et al, 'Aid effectiveness and vulnerability'.

${ }^{64}$ Renn, on file with author

${ }^{65}$ Türk and Eyster, 'Strengthening Accountability in UNHCR'.
} 
or bureaucratic practices: such an outcome also requires senior management who are willing and able to meet such objectives, in contexts where resources are extremely scarce, the working environment is difficult, and human needs are urgent. As for biometrics, only where refugees are registered biometrically will UNHCR need to consider the security of large amounts of sensitive biometric data as a key aspect of protection. Moreover, the challenges that emerge from the use of biometric technology will vary with context: for example, the difficulties encountered in refugee camps differ from those encountered in urban contexts-where, for example, cross-border movements and outreach are greater concerns than in camp settings. In other words, how is it possible to assume that biometrics has universal applicability, and an attending capacity to enhance accountability in UNHCR's refugee assistance practices globally, when the technology is being implemented under vastly different circumstances where it confronts different challenges and yields different results? Paradoxically the only 'universal' effect seems in fact to be the production of biometric refugee data - an effect that may challenge rather than strengthen UNHCR's accountability towards refugees considering the current lack of official policies that address a number of critical issues, including the sharing of biometric refugee data. Following this line of reasoning, CBIs will look radically different in contexts with or without biometric registration, and also functioning very differently in countries according to the advancement of the financial technology infrastructure.

As accountability technologies, all three yield an understanding of protection in which quantification, measurability, and accuracy are assigned greater value than qualitative perspectives and contextual understanding. But quantification, measurability, and accuracy do not necessarily ensure a "benign, universal" notion of accountability. Assuming that the main objective is to attend to refugee protection needs, including new ones that emerge as UNHCR changes its practices, what if specific, techno-bureaucratic practices create specific accountability issues, and those issues vary with context? In following, we want to illustrate to how new protection needs may be co-produced through accountability-technologies.

One example of the ways in which such needs can be created is the use of interview guides, needs assessments, and resettlement forms to protect 'women at risk'. While the recognition of gendered harm as relevant to refugee protection has been considered progressive, this recognition may also increase the vulnerability of victims as their data are entered through scripts that might be reversed to allow for identification and their stories are uploaded by way of more or less well-protected files into sometimes insecure networks. Similarly, biometric refugee data gives rise to a protection need that did not exist before: the need to protect the 
digital "refugee body" - and with the rise of CBIs, the integrity of the relationship between parts of the refugee body (the iris) and access to assistance.

Technical problems that persist over time (and where there is organizational resistance towards acknowledging the structural nature of problems) may compromise protection efforts. However, an additional dynamic arises with the technological determinist claim that a solution work as intended: In 2007, commenting on early challenges associated with Focus, OIOS urged UNHCR to "thoroughly address as many remaining technical anomalies in the software as possible before bringing it to scale throughout the agency" ${ }^{\prime 66}$. UNHCR responded that it would not release a substandard product, and stated that the reference to "technical anomalies" unfairly implied that "UNHCR might consider putting a product out that did not work well." 67 A 2010 OIOS audit indicated that security requirements had still "not been clearly defined and documented for the Focus system"68, compromising the "confidentiality, integrity and availability of data processed and stored." OIOS further noted that "the absence of defined security architecture adequate for the different sizes and location of field offices exposes UNHCR to risks of data being accessed by unauthorized users," resulting in potential data breaches or loss, and that hosting Focus on a public domain server exacerbated the risks. ${ }^{69}$ Over the next couple of years, UNHCR failed to upgrade Focus in a satisfactorily manner. In 2015, the Board of Auditors observed that consultations were underway to find "alternative commercial software applications" to provide "a long-term solution" for UNHCR's tool for result-based management. ${ }^{70}$

Hence, vulnerability is co-produced by individual protection officers failing to comply with their job description and structural failures of policy (UNHCR continues to be criticized for lacking policy and operating procedures with respect to data protection) and technology implementation. Protection efforts may be compromised when the technology doesn't work at all, or doesn't work as efficiently and effectively as expected-but such efforts may also be compromised when technological measures, or the mere presence in humanitarian cyberspace, engender vulnerabilities. ${ }^{71}$

\footnotetext{
${ }^{66}$ UN OIOS, 'Inspection', 25, para 32.

${ }^{67}$ UN OIOS, 'Inspection', 25, para 32.

${ }^{68}$ UN OIOS, 'Audit of Focus', 10, para 45.

${ }^{69}$ UN OIOS, 'Audit of Focus', 10, para 4547.

${ }^{70}$ Board of auditors, 'Recommendations'

${ }^{71}$ Sandvik, 'The Humanitarian Cyberspace'
} 


\section{Governance issues}

Even though RBM, biometrics and CIBs have been emphasized as tools for improving international refugee protection, little attention has been paid to the ways in which these technobureaucratic practices infuse protection with specific value and meaning. Taking as our starting point that humanitarian protection practices - including the uptake of new accountability technologies - must be understood not simply as passive 'tools' but rather as having constitutive effects, we have called attention to the risk of a potentially critical disjoint between the emergence of new refugee vulnerabilities and humanitarian conceptions of protection in which these new vulnerabilities remain invisible. For, when moving from seeing 'accountability technologies' as techno-bureaucratic solutions that can serve as panaceas for the different (and possibly contradictory) accountability demands faced by UNHCR, to focusing on the politics of these measures, various productive effects become visible, including the following two concerns.

First, when technologies fail to perform as expected, what is the impact on accountability, and on refugee protection and safety? For example, who is accountable if biometrics - or the programming of a CBI - fails by mistakenly classifying a "legitimate" refugee as one who is ineligible for aid? Equally important, what options do refugees have for even raising such issues ${ }^{72}$ Scenarios in which questions like these arise, demonstrate that the ability of techno-bureaucratic practices to improve downward accountability cannot be taken for granted. Technology does not always work as intended, and the risk that technical failures may translate into humanitarian failures illustrates how techno-bureaucratic practices can potentially undermine UNHCR's ability to provide protection, especially if framed in a manner that disregards rather than calls attention to the politics and productive effects of these 'technical solutions'. Indeed, a fuller understanding of accountability would seem to call not only for a continuous evaluation of how specific technologies may give rise to new protection needs, but for the recognition that accountability is not a process that can be "fixed"; instead, it requires continuous attention to the productive aspects of UNHCR's own practices-including those that it may be tempting to dismiss as "merely" technical or bureaucratic.

Second, governance issues also arise where the use of 'accountability technologies' give rise to new protection needs. The introduction of new technology-in particular, the collection of biometric refugee data - is constitutive of a new type of "refugee body" with new protection needs. Despite UNHCR's assumption that the implementation of such technologies can simply

\footnotetext{
72 Experimentation in Humanitarian Locations'
} 
and straightforwardly enhance downward accountability, it actually places new demands on UNHCR for the protection of sensitive data, a responsibility that has important implications for the safety of biometrically registered refugees. Building on biometric registration, CBIs coproduce customers: "CBIs using technology or other financial services can provide a portal to a wider range of financial services-like bank accounts, savings, and credit to those who previously did not or could not access them". ${ }^{73}$ What doors are being opened to which market actors, how are they being held accountable to refugees, and what does the financialization of refugee protection mean for UNHCR?

Collecting ever-more-detailed information that gets digitalized and therefore can be plugging it into software that aggregates and disaggregates for potentially unforeseen uses, introduces new risks that we have yet to fully grasp - let alone find adequate ways of protecting refugees from. Thus, instead of simply seeing new digital technologies as technical solutions that can solve longstanding accountability challenges, it would seem more promising to take seriously the politics of these technologies, including their productive effects. Doing so would call attention to the risk of harmful consequences that UNHCR could arguably be held accountable for.

\section{Conclusion}

In short, our analysis has not only showed how constitutive processes around the introduction of each of the three 'accountability technologies' examined in this article, contribute to the production of particular understandings of how, what, and whom it is important for UNHCR to protect. More specifically, to understandings that implicitly focus debates about protection on those aspects of 'the social' that are (made) legible and quantifiable, a focus which may translate into debates about accountability where the role of human judgement, political considerations, logistical constraints, and technical malfunctions are omitted. More than that, new "bodies" and materialities are produced - an insight that reveals how new technology can bring about new accountability needs and give rise to critical accountability gaps. In the case of RBM and CBIs, for example, this may occur if, in the quest for "measurability," important dimensions are excluded from the definition of protection or vulnerability; in the case of biometrics, gaps may develop if new protection needs are left out of the meaning assigned to protection.

As noted earlier, donors tend to stress the ways in which RBM, biometrics and CBIs can improve upward accountability (e.g., by providing more reliable numbers and more

\footnotetext{
${ }^{73}$ Berg and Seferis, 'Protection outcomes'.
} 
efficient aid delivery), while critics tend to focus on the risks for downward accountability (e.g., because refugees are not informed about how data will be used; because certain forms of impact can be impossible to measure). This contrast presages the re-emergence of an old critique: namely, that of an increasing "gap between financial accountability and moral accountability". ${ }^{74}$ Accordingly, it is important to note that the turn to different accountability technologies is inseparable from trends in the broader political landscape: for example, the securitization and marketization of humanitarian practices are creating new pressures on humanitarians to meet new accountability expectations by taking on new methods and tools, including CBIs, biometrics and RBM. Whilst the attractiveness of these three technologies depend upon assumptions about their apolitical nature, each technology is in fact bound up with specific forms of political organisation and structures of power ${ }^{75}-$ be it around New Public Management philosophies and linear modelling of clear causal relationships (RBM), securitization logics (biometrics) or financial inclusion as neoliberal security governance (CBI).

Rather than taking for granted that these initiatives will automatically improve UNHCR's upward accountability, we should examine this assumption and the practices that it informs. For example, given the extent to which a large number of states have increasingly implemented biometric technologies as part of their 'counter-terror' efforts, using biometrics as a humanitarian 'accountability technology' is arguably inseparable from this broader political context. Surely, adding biometrics to UNHCR's refugee protection practices will not in itself render state accountability for asylum, refugee protection, and funding practices any less important. Nor will it necessarily improve downward accountability; on the contrary, biometrics should be understood as potentially adding new dimensions to UNHCR's accountability to registrants. Together these technologies not only illustrate how a strong focus on quantification underlies UNHCR's understanding of what it means to be accountable to international refugee law. Analysing these three technologies chronologically also suggests that within this quantification focus we have witnessed a shifted from the quantification of impact at the level of humanitarian protection endeavours, to the quantification of individual recipient with biometrics and with CBI.

A key difficulty with CBIs, RBM and biometrics is that the problems they are deployed to solve are political, not merely technical. Although UNHCR uses these tools to increase the accountability of international protection, what must be added, however, is that implementing

\footnotetext{
${ }^{74}$ Harrell-Bond et al. 1992:219

${ }^{75}$ Jasanoff 2004:31
} 
these tools renders refugee protection practices more "governance-like": the broad vision of accountability reflects a conception of a humanitarian governance that can promise, improve, and perform, but that ultimately remains a matter of voluntary commitments, outside the binding structures of human rights law or the democratic contract between a state and its citizens.

\section{Bibliography}

Allen, Richard, and Angela L. Rosi. 'Measure for Measure: A Field-Based Snapshot of the Implementation of Results Based Management in UNHCR'. United Nations High Commissioner for Refugees Policy Development and Evaluation Service, 2010.

Alsalem, Reem and Frauke Riller. 'UNHCR slashes waiting time, clears backlog of Syrian registrations in Jordan' UNHCR, 03 October 2013 [http://www.unhcr.org/news/makingdifference/2013/10/524d5e4b6/unhcr-slasheswaiting-time-clears-backlog-syrian-registrations-jordan.html]

Asdal, Kristin, Brita Brenna, and Ingunn Moser, eds. Technoscience: The politics of interventions. Oslo Academic Press, 2007.

Barnett, Michael. 'Humanitarianism with a Sovereign Face: UNHCR in the Global Undertow'. The International Migration Review: IMR; New York 35, no. 1 (Spring 2001): 244-77.

Barnett, Michael N. "Humanitarian governance." Annual Review of Political Science 16 (2013): 379-398.

Berg, Michelle, and Louisa Seferis. "Protection outcomes in cash based interventions: a literature review." Danish Refugee Council, UNHCR, and ECHO (2015).

Betts, Alexander, Gil Loescher, and James Milner (year) The United Nations High Commissioner for Refugees (UNHCR): The Politics and Practice of Refugee Protection. Vol. 2008. Abingdon: Routledge.

Bradley, M. 'UNHCR and Accountability for IDP Protection in Colombia'. In UNHCR and the Struggle for Accountability: Technology, Law and Results-Based Management, by Kristin Bergtora Sandvik and Katja Lindskov Jacobsen, 184. Abingdon: Routledge, 2016.

Burns, Jimmy and Frances Williams, 'United Nations High Commissioner for Refugees: Special Report, Refugee's Agency Lost in Wilderness of Bungling and Waste' (Financial Times, July 29, 1998 at 7).

Cole, Simon A., and Alyse Bertenthal. "Science, Technology, Society, and Law." Annual Review of Law and Social Science 0 (2017).

Crisp, Jeff. 'epatriation Under Conflict: A Review of the Encashment Programme for Afghan Refugees in Pakistan EVAL/ENC/14 Central Evaluation Section; 1994

Crisp, Jeff. A State of Insecurity: The political economy of violence in Kenya's Refugee Camps, African Affairs, Volume 99, Issue 397, 1 October 2000, Pages 601-632 
Dallal E. Stevens. 'Rights, Needs or Assistance? The Role of the UNHCR in Refugee Protection in the Middle East'. International Journal of Human Rights 2015, no. 2 (n.d.): 23.

Dunlop, Emma, Indications of progress? Assessing the use of indicators in UNHCR operations, July 2011, ISSN 1020-7473, available at: http://www.refworld.org/docid/4e55ec4e2.html [accessed 19 November 2017]

Ebrahim, Alnoor, and V. K. Rangan. 'The Limits of Nonprofit Impact: A Contingency Framework for Measuring Social Performance'. Working Paper. Haward Business School, 2010. http://www.hbs.edu/faculty/Publication\%20Files/10-099.pdf.

Flint, N. Easier Said Than Done: A Rewiew of Results-Based Management in Multilateral Development Institutioons. Hrefordshire, UK: Wernddu Pontrilas, 2003.

Franke, Mark FN. "Refugee registration as foreclosure of the freedom to move: the virtualisation of refugees' rights within maps of international protection." Environment and Planning D: Society and Space 27.2 (2009): 352-369.

Ghelli, Tina, and Leo R. Dobbs. 'UNHCR Pilots New Biometrics System in Malawi Refugee Camp'. UNHCR News and Stories, 2014. http://www.unhcr.org/news/makingdifference/2014/1/52dfa8f79/unhcr-pilots-newbiometrics-system-malawi-refugee-camp.html.

Ghufran, Nasreen. 'Afghan Refugees in Pakistan Current Situation and Future Scenario'. Policy Perspectives Volume 3, no. No. 2 (July 2006): 28.

Gilert, Heidi and Lois Austin. 'Review of the Common Cash Facility Approach in Jordan' 2017 http://www.cashlearning.org/downloads/calp-ccf-jordan-web.pdf 2017

Hussain, Misha. "'Ghost” Malian Refugees Show Abuse of U.N. Registration System'. Reuters, 21 March 2014. https://www.reuters.com/article/us-burkina-refugees/ghostmalian-refugees-show-abuse-of-u-n-registration-system-idUSBREA2K13Y20140321.

Ismail, Yante, and Kitty McKinsey. 'Fingerprints Mark New Direction in Refugee Registration'. UNHCR, News and Stories. Accessed 6 September 2017. http://www.unhcr.org/news/latest/2006/11/456ede422/fingerprints-mark-newdirection-refugee-registration.html.

Jacobsen, Katja Lindskov. "Experimentation in Humanitarian Locations: UNHCR \& Biometric Registration of Afghan Refugees.” Security Dialogue (2015) 46 (2): 144164.

Jacobsen, Katja Lindskov. "On Humanitarian Refugee Biometrics and New Forms of Intervention." Journal of Intervention and Statebuilding (2017): 1-23.

Jacobsen, Katja Lindskov. 'UNHCR, Accountability and Refugee Biometrics'. In UNHCR and the Struggle for Accountability: Technology, Law and Results-Based Management, by Kristin Bergtora Sandvik and Katja Lindskov Jacobsen, 184. Abingdon: Routledge, 2016.

Jasanoff S. 1995. Science at the Bar: Law, Science, and Technology in America. Cambridge, MA: Harvard Univ.Press

Jasanoff, 2004. States of knowledge: the co-production of science and the social order. Routledge. 
Kagan, Michael. 'Is Truth in the Eye of the Beholder - Objective Credibility Assessment in Refugee Status Determination' Georgetown Immigration Law Journal 17, no. 3 (2003 2002): 367-416.

Kelley, Ninette, Peta Sandison, and Simon Lawry-White. 'Enhancing UNHCR's Capacity to Monitor the Protection, Rights and Well-Being of Refugees'. United Nations High Commissioner for Refugees Evaluation And Policy Analysis Unit, 2004. http://www.unhcr.org/research/evalreports/40d9781d4/enhancing-unhcrs-capacitymonitor-protection-rights-well-being-refugees.html.

Khogali, Hisham, Lynette Larsen, Kate Washington and Yara Romariz Maasri (2014) Aid effectiveness and Vulnerability Assessment Framework: determining vulnerability among Syrian refugees in Jordan, Field Exchange 48.

http://www.ennonline.net/fex/48/aideffectiveness

Krever, Tor. "Quantifying Law: legal indicator projects and the reproduction of neoliberal common sense." Third World Quarterly34.1 (2013): 131-150.

Loescher, Gil. 'UNHCR and the Erosion of Refugee Protection'. Forced Migration Review 2001, no. 10 (2001): 28-30.

Lohne, Kjersti, and Kristin Bergtora Sandvik. "Bringing Law into the Political Sociology of Humanitarianism." Oslo Law Review1.01 (2017): 4-27.

Merry, Sally Engle. The seductions of quantification: Measuring human rights, gender violence, and sex trafficking. University of Chicago Press, 2016.

MOPAN (Multilateral Organisation Performance Assessment Network). 'Multilateral Organisation Performance Assessment Network: Synthesis Report - United Nations High Commissioner for Refugees (UNHCR)', January 2014.

Morris, Christopher. 'Investigating Evaluation as an Accountability Mechanism by International Non-Governmental Organizations Working in Humanitarian Relief'. University of British Columbia, 2014. doi:10.14288/1.0166082.

Oritz, Alfredo, and Peter Taylor. 'Learning Purposefully in Capacity Development: Why, What and When to Measure?' Oponion paper prepared for IIEP. Institute of Development Studies, UK, 2009. file:///C:/Users/dlg644/Downloads/fulltext.pdf.

Otieno, Peter, and Dorothy Gazarwa. 'Joint Assessment Mission - Kenya Refugee Operation: Dadaab (23 - 27 June 2014) and Kakuma (30 June - 1 July 2014) Refugee Camps'. UNHCR \& WFP, 2014. http://www.unhcr.org/54d3762d3.pdf.

Pallis, Mark. 'The Operation of UNHCR's Accountability Mechanisms'. New York University Journal of International Law and Politics 37 (2005 2004): 869-918.

Rahman, Z (2017) Irresponsible data? The risks of regisetering the Rohyngia

Ramalingam, Ben, John Mitchell, and Kristen Smart. 'Counting What Counts: Performance and Effectiveness in the Humanitarian Sector'. Review of Humanitarian Action, 2009. http://www.alnap.org/resource/5666.

Jefferey Riecke (2017) Refugees and Humanitarian Assistance: Which Kind of Aid Is Best? https://cfi-blog.org/2017/02/14/refugees-and-humanitarian-assistance-which-kind-ofaid-is-best

Rietjens, Sebastiaan, Joseph Soeters, and Willem Klumper. 'Measuring the Immeasurable? The Effects-Based Approach in Comprehensive Peace Operations'. International 
Journal of Public Administration 34, no. 5 (19 April 2011): 329-38.

doi:10.1080/01900692.2011.557816.

Sandvik, Kristin Bergtora. 'Blurring Boundaries: Refugee Resettlement in Kampala-between the Formal, the Informal, and the Illegal'. PoLAR: Political \& Legal Anthropology Review 34, no. 1 (May 2011): 11-32. doi:10.1111/j.1555-2934.2011.01136.x.

Sandvik, Kristin Bergtora, Katja Lindskov Jacobsen, and Sean Martin McDonald. "Do no harm: A taxonomy of the challenges of humanitarian experimentation." International Review of the Red Cross (2017): 1-26.

Sandvik, Kristin Bergtora; \& Katja Lindskov Jacobsen, eds. (2016) UNHCR and the Struggle for Accountability Technology, law and results-based management. Abingdon, Oxon: Routledge. Routledge Humanitarian Studies

Sandvik, Kristin Bergtora (2016) 'How accountability technologies shape international protection: results-based management and rights-based approaches revisited', in Sandvik, Kristin Bergtora; \& Katja Lindskov Jacobsen, eds, UNHCR and the Struggle for Accountability, Technology, law and results-based management. London: Routledge Humanitarian Studies (138-158).

. 'The Humanitarian Cyberspace: Shrinking Space or an Expanding Frontier?' Third World Quarterly 37, no. 1 (2 January 2016): 17-32. doi:10.1080/01436597.2015.1043992.

Scott, J. C. 1998. Seeing like a state: how certain schemes to improve the human condition have failed. Yale University Press

Schimmel, Volker (2014) UNHCR cash programming in emergencies - implementation and coordination experience during the Syrian refugee response in Jordan. Field Exchange \# 48. http://www.ennonline.net/fex/48/unhcrcash

Slaughter, Amy, and Jeff Crisp. 'A Surrogate State? The Role of UNHCR in Protracted Refugee Situations'. Research Paper No. 168. News Issues in Refugee Research. UNHCR. Accessed 6 September 2017. http://www.unhcr.org/research/working/4981cb432/surrogate-state-role-unhcrprotracted-refugee-situations-amy-slaughter.html.

Storey, Hugo. 'The Meaning of "Protection" within the Refugee Definition'. Refugee Survey Quarterly 35, no. 3 (1 September 2016): 1-34. doi:10.1093/rsq/hdw012.

Suhrke, Astri, and Kathleen Newland. 'UNHCR: Uphill into the Future'. The International Migration Review 35, no. 1 (2001): 284-302. doi:10.2307/2676062.

Turk, Volker, and Elizabeth Eyster. 'Strengthening Accountability in UNHCR'. International Journal of Refugee Law 22, no. 2 (1 July 2010): 159-72. doi:10.1093/ijrl/eeq013.

UNHCR. Emergency Handbook: Accountability to Affected Populations (AAP). UNHCR's Handbook for Emergencies 4, 2015. https://emergency.unhcr.org/.

UNHCR 2012. 'Modern Technology Helps Meet the Needs of Refugees in South Sudan'. UNHCR, News and Stories, 27 December 2012. http://www.unhcr.org/news/makingdifference/2012/12/50dc5a309/moderntechnology-helps-meet-needs-refugees-south-sudan.html.

UNHCR. 2013. 'Request for Proposal: No. RFP/2012/507 - For the Provision of a Biometric Identity Management System' 31 January 2013. United Nations High Commissioner for Refugees [http://www.unhcr.org/50c85dd69.pdf] 
(2016) Cash Based Assistance. UNHCR Fact Sheet [http://www.unhcr.org/58f5c3987] 'Practical Guide to the Systematic Use of Standards and Indicators in UNHCR Operations'. UNHCR Geneva: Division of Operational Services, February 2006. http://www.unhcr.org/statistics/unhcrstats/40eaa9804/practical-guide-systematic-usestandards-indicators-unhcr-operations.html.

- 'Policy on Cash Based Interventions', UNHCR 2016

[http://www.unhcr.org/protection/operations/581363414/policy-on-cash-basedinterventions.html]

/Division of Programme Support and Management (DPSM), (n.d.g) 'Cash-based interventions'. [http://www.unhcr.org/protection/basic/55005bdd9/key-initiativescash-based-interventions.html]

Operational Guidelines for Cash-Based Interventions in Displacement Settings, 4 February 2015, UNHCR/OG/2015/3, available at:

http://www.refworld.org/docid/54d387d14.html [accessed 19 November 2017] (n.d.a) Refugee Assistance Information System (RAIS): Interagency Tool for:

Vulnerability Scoring requesting new beneficiary lists - JORDAN Mission. Available at data.unhcr.org/syrianrefugees/download.php?id=12876

United Nations. 'Implementation of the Recommendations of the Board of Auditors Contained in Its Reports on the United Nations Funds and Programmes for the Year Ended 31 December 2014'. United Nations, September 2015. http://undocs.org/en/A/70/338/Add.1.

- 'Voluntary Funds Administered by the United Nations High Commissioner for Refugees: Financial Report and Audited Financial Statements for the Year Ended 31 December 2010 and Report of the Board of Auditors'. General Assembly, Official Records. United Nations, 2010.

http://www.unhcr.org/excom/unhcrannual/4e60a7339/voluntary-funds-administeredunited-nations-high-commissioner-refugees.html.

UN OIOS (2007) Inspection on Results-Based Management practices [INS-07-005]" relating to the Office of the United Nations High Commissioner for Refugees. available at https://wikileaks.org/wiki/Office_of_the_United_Nations_High_Commissioner_for_R efugees:_Inspection_on_Results-Based_Management_practices_(INS-07005),_21_Dec_2007

UN OIOS (2010) Audit of Focus syste, Assignment No. AR2010/166/02 https://usun.state.gov/sites/default/files/organization_pdf/159760.pdf

Verdirame, Guglielmo, Barbara Harrell-Bond, Zachary Lomo, and Hannah Garry. Rights in Exile: Janus-Faced Humanitarianism. New York and Oxford: Berghan Books, 2005.

Walkup, Mark. 'Policy Dysfunction in Humanitarian Organizations: The Role of Coping Strategies, Institutions, and Organizational Culture'. Journal of Refugee Studies 10, no. 1 (1 January 1997): 37-60. doi:10.1093/jrs/10.1.37.

Wilde, Ralph. 'Quis Custodiet Ipsos Custodes: Why and How UNHCR Governance of Development Refugee Camps Should Be Subject to International Human Rights Law Note'. Yale Human Rights \& Development Law Journal 1, no. 5 (1998): 107-28. 